\title{
Exploring Immersive Technology for Architecture that Empowers Marginalized People: An Australian Postgraduate Case Study in Design Education
}

\author{
Waldemar Jenek \\ Queensland University of Technology | CSIRO's Data61, Brisbane, Australia. \\ Glenda Caldwell 무 \\ Queensland University of Technology Brisbane, Australia. \\ Jared Donovan \\ Queensland University of Technology, Brisbane, Australia. \\ Veronica Garcia-Hansen \\ Queensland University of Technology, Brisbane, Australia. \\ Matt Adcock \\ CSIRO's Data61, Canberra, Australia. \\ Mingze XI \\ CSIRO's Data61, Canberra, Australia. \\ Kavita Gonsalves \\ Queensland University of Technology Brisbane, Australia.
}

Received: May 10th 2021, Revised: June 20th 2021, Accepted: June 22nd 2021.

Refer: Jenek, W., Caldwell, G., Donovan, J., Garcia-Hansen, V., Adcock, M., XI M., Gonsalves, K., (2021), Exploring Immersive

Technology for Architecture that Empowers Marginalized People: An Australian Postgraduate Case Study in Design Education, Journal of Design Studio, V.3, N.1, pp 117-123,

W. Jenek ORCID: 0000-0001-8771-9111, G. Caldwell ORCID: 0000-0003-0837-9310, J. Donovan ORCID: 0000-0002-8025-1947, V. Garcia-Hansen 0000-0001-5934-5554, M. Adcock ORCID: 0000-0001-6191-9887, M. XI ORCID: 0000-0003-1291-4136, K. Gonsalves ORCID: 0000-4769-2334

DOI: $10.46474 /$ jds.935636 https://doi.org/10.46474/jds.935636

\begin{abstract}
This paper examines a case study part of an ongoing $\mathrm{PhD}$ research at Queensland University of Technology, Brisbane, Australia. The case study investigates how architecture students can employ media architecture design with real-time-render software tools to empower people without permanent residence. As part of the assignment students developed a media architecture structure during the semester to support people who are facing homelessness. The target participants of this study were master architecture students at Queensland University of Technology. Students participated in an online survey and semi-structured interviews at the end of the semester to provide feedback about their learning experience during the master class. The data was analysed with thematic analysis. The study results explore the potential of technology to face the ongoing issues of homelessness. It opens the discussion how media architecture can be utilised to target issues such as displacement and marginalization. The results allow to refine future studio education and endeavour how to employ real-time software in a studio context.
\end{abstract}

Keywords: Design Education, Design Studio, Immersive Design Environment, Media Architecture, Homelessness 


\section{Journal of \\ Design Studio}

v:3 n:1 July 2021

\section{Introduction}

Homelessness is one of the growing problems in all the countries around the world (Huey, 2012). Homelessness is a complex social issue in many societies as it caused by several different reasons to different kind of people. A homeless individual seeks primary night-time residence shelter homes that provide short-term accommodation (Hersberger, 2005). The Health Department of the Australian government defines homelessness into three levels (Australian Government, 2021; Chamberlain \& MacKenzie, 1992):

- primary homelessness - living on the streets, in parks, in deserted buildings;

- secondary homelessness - living in temporary shelters such as refuges, emergency accommodation or sleeping on a friend's couch;

- tertiary homelessness - living in a boarding room.

Within these levels, homeless people are fronting an absence of connection with friends and family or society in general. Besides, not being able to control personal matters which can lead to physical and mental health issues (Le Dantec \& Edwards, 2008). Architecture can be one of the critical enablers of our society. In this studio, we investigated how architecture can go beyond its role in society and tackle a social issue such as homelessness. The focus of this design studio was to discover solutions for people who experience impacts of marginalisation and displacement, with an emphasis on homeless people in Australia. The purpose of the imaginary proposals is to engage policy and stakeholders and the general public, to acknowledge current issues and imagine alternative futures. Students discovered opportunities without the limitation of current real-life, but by imagining how they might no longer be relevant soon. Possibilities of Roma Street and Fortitude Valley Station sites were actively explored in Brisbane, Australia.
Students identified groups of marginalised communities and specific issues that must be addressed. Projects included in-depth analysis, identification of particular problems and exploration of possible solutions. Therefore, we introduced students to the concepts of media architecture and immersive virtual design environments. In this case study, virtual reality was used with real-time rendering software and VR-headsets to investigate the design of media architecture and how media architecture can be employed to empower marginalized and displaced communities.

\section{Background}

Media architecture can refer to build structures that incorporate media to facilitate communication with the public on an architectural scale (Brynskov et al., 2015; Dalsgaard \& Halskov, 2017). Media architecture is an emerging field that continues to advance as technology enhances (Caldwell, 2016). Media architecture is usually not included in many architecture curricula (Zhigang as cited in Haeusler et al., 2012). Therefore, we introduced students to concepts to further explore, such as entertainment media architecture which are project illumining buildings interconnected to business, retail, entertainment or commercial intentions (Fong \& Chan, 2019), besides, building that include a media façade solution (Dalsgaard \& Halskov, 2010) and interactive media participatory projects that empower local public engagement (Caldwell \& Foth, 2014). It is challenging with traditional architectural design tools to capture the function and dynamic of media architecture. Therefore, we proposed to employ immersive technology for the design process. While other research studies such as Castronovo et al., 2017; Knowlton, 2016; Kvan, 2001; and Maher et al., 2012 explore how to implement technology in a traditional design studio context, this studies emphases on immersive virtual design environments for media architecture. It is vital to explore techniques for learning architectural

Technology for Architecture that Empowers Marginalized People: An Australian Postgraduate Case Study in Design Education, 


\section{Journal of \\ Design Studio}

v:3 n:1 July 2021

design that allow students to prototype and test media architecture proposals. The ongoing media technology development allows information to be communicated in various ways, at different scales, and in physical and digital space (Parker et al., 2018). There is ongoing research on how architects, urban planners, designers and engineers can benefit from digital media (Dalsgaard \& Halskov, 2017). As a result, media architecture will continue to evolve as technology advances (Fong \& Chan, 2019). Integrating digital media is into architecture and urban planning will develop and potentially become more of a critical enabler of societal patterns (Caldwell \& Foth, 2014). This responsibility fuels the necessity for intervention concerning this globally felt issue, such as homelessness.

\section{Study Design}

This case study is the third case part of an ongoing $\mathrm{PhD}$ research (Jenek et al., 2020, Jenek et al., 2021), therefore, we made decisions based on our previous finding, and followed the same analysis approach. In order to compare student experience in the future. It was conducted as part of a master architecture studio in Australia from July 2020 to December 2020. The participants were master architecture students and close to graduate. Many of them were already working in architecture industry. The design studio had 37 students, who were taught by the course coordinator and the principal researcher. The study was designed as a part of a studio curriculum focusing on marginalised and displaced communities and individuals, particularly homelessness. The studio time was once a week for 6 hours during the whole semester, in which tutors provided general feedback to student project and delivered a lecture about homelessness, media architecture, and real-time-render software and design studio activities. This set up supported students to explore the design brief and research potential displaced groups to support their architecture design intervention. Students had the opportunity to design a media architecture structure as part of the building design. Figure 1 is an example of the student work at the end of the semester. The image shows a wall with a projection that allows users to express themselves and been recognised in society. Homelessness continues to be a complex issue in society; with these prototypes, the studio endeavours exploration of solutions for people and communities who suffer from marginalisation and displacement in Australia.

The proposed projects provided an imaginary framework in each student submission targeting a different type of risk groups such as young adults, indigenous backgrounds, drug addict, chosen by each student. Each project aims to reintroduce individuals who are at risk of becoming homeless in future.

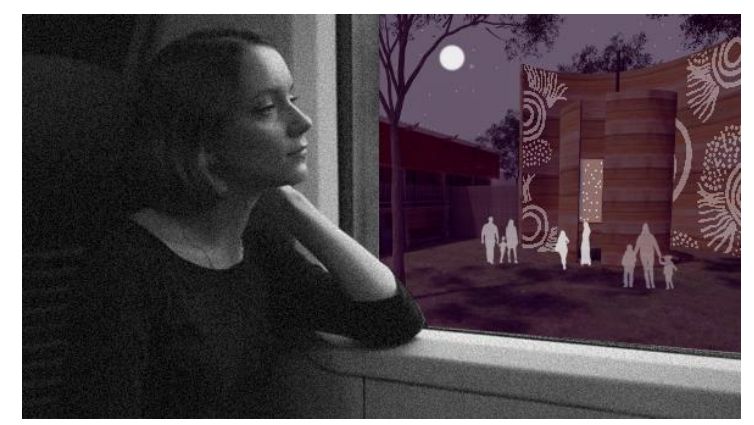

Figure 1: Projection wall by Kate Freshwater

Students employed a range of software tools since all of them already had at least a bachelor degree in architecture. The principal researcher has introduced design studio participants to Twinmotion (Epic Games, 2020) real-time immersive 3D architectural visualisation software for virtual reality. Some of the students used Lumion, a similar real-time immersive 3D architectural visualisation software solution (Lumion, 2021). Most students designed their projects in Revit and a few in Archicad. Both software products are common architectural drawing and 3D modelling software (Autodesk, 2021; Graphisoft, 2020). We introduced Twinmotion in more depth as virtual environment tools and media architecture concepts to students to complete a design task. Students explored their ideas with traditional tools such as physical model and drawings but also modelled their design ideas with the CAD Software. In addition, some students animated their design in real-time software or created an animated GIF. 


\section{Journal of \\ Design Studio}

v:3 n:1 July 2021

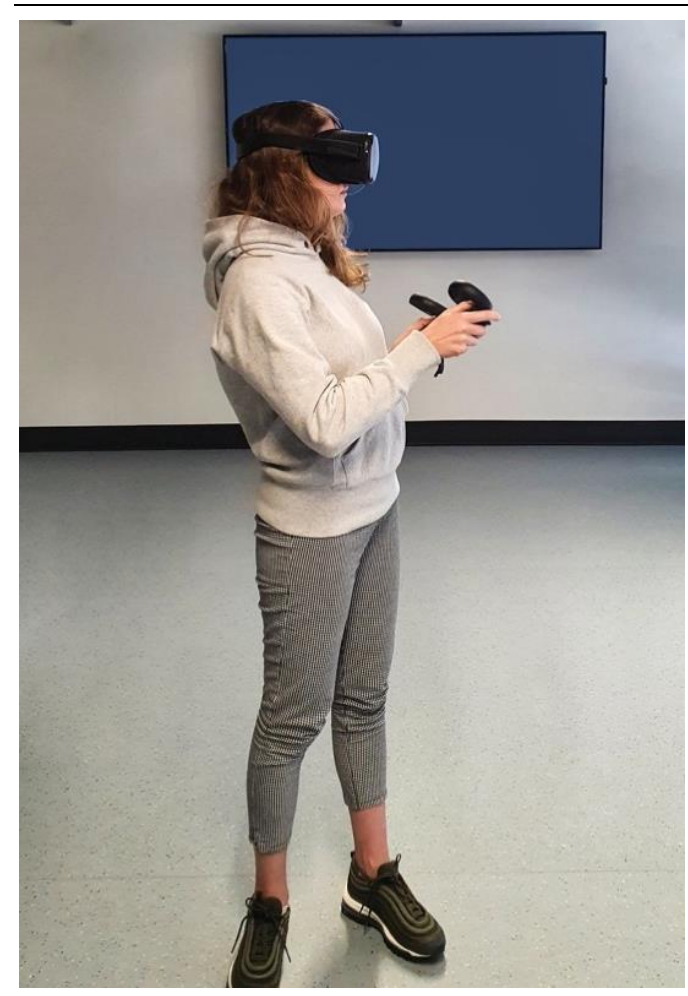

Figure 2: Student using VR Headset, photo by the author

Most students were able to study their ideas with a virtual reality headset Oculus Rift and Oculus S, which were available during class seen in Figure 2. The Oculus Rift headset is a virtual reality system that fully immerses user to feel present in the digital realm (Desai et al., 2014). Due to the limited number of devices and COVID 19 restrictions, only a few students used this opportunity of using Oculus Rift headset.

\section{Data Collection}

This case study paper expands on our findings (Jenek et al., 2020, Jenek et al., 2021) to further examine the impact of immersive virtual design environments in a real-world context. Since the study is part of the ongoing $\mathrm{PhD}$ research, a variation of Ethical clearance was submitted and approved from the Queensland University of Technology QUT Human Research Ethics Committee and complied with the requirements for a negligible or low-risk application (approval number: 1900000811). The principal researcher author communicated to participating students that critical evaluations help improve the design studio content and student experience. The recruiting process took place in June 2020. Students were able to announce a preference between 4 different master themes, and in addition to that they could decide at the end of the semester if there are willing to participate in this research. The case study employed qualitative data collection methods such as observations, semi-structured interviews $(n=8)$ and online-surveys $(n=9)$ with participating students, conducted by the lead author.

\section{Data Analysis}

The principal researcher conducted a survey, semi-structured interviews and observations during studio time to evaluate the learning experience. We employed thematic analysis to organise the qualitative data (Braun \& Clarke, 2006). We following steps of 1 .familiarisation with the data, 2. initial coding, 3. searching for themes, 4. reviewing themes, 5. defining themes, 6. reporting findings (Braun \& Clarke, 2006). We employed Keller's ARCS motivational model to explore the attention, relevance, confidence and satisfaction of participating students to evaluate the learning experience (Keller, 2010). The results are presented in the following section organise through the ARCS model. The principal researcher author communicated to participating students that critical evaluations help improve the design studio content and student experience. This case study is the third case part of an ongoing $\mathrm{PhD}$ research (Jenek et al., 2020, Jenek et al,. 2021). Therefore, we made decisions based on our previous finding, and followed the same analysis approach. In order to compare student experience in the future.

\section{Findings}

We organised the emerging themes under the ARCS model sub-headings as follows:

\section{Attention}

A leading emerging theme in the data is the major interest in the field of immersive technology to tackle real-world problems such as homelessness. Students reported virtual 


\section{Journal of \\ Design Studio}

v:3 n:1 July 2021

design environments are a valuable addition to traditional design approaches.

Immersive design environment: Students illustrated the advantage of an immersive experience within a real-time-rendering software and using the Oculus Rift Headset. They described this approach supported their design decisions regarding dynamic design proposal such as facade projection. Students described the immersive experience technology as appealing, but they critiqued the heavy headset and mentioned that they would not use it for a more extended time. Students explained it is beneficial to employ immersive technologies to tackle real-world issues such as homeless.

\section{Relevance}

Participants emphasised the relevance of immersive technologies for their professional career. In particular, one student reported that at the beginning of the semester, the student thought virtual design environments are only an addition to the design process with traditional design tools. They reported having transformed their opinion and see a benefit in capturing the dynamics of media architecture structures, such as changing light sources, displays and moving elements.

Previous learning experiences: One participant explained that they had been fascinated by their peers who could produce highly realistic rendering with software tools as v-ray and critiqued that there was no design course in which they would learn about how to create thous outputs. They expressed a profound learning success after the design course in reporting that they feel more capable of achieving an appropriate visualisation.

Identified content issue: Research precipitants described that there sometimes was confusion between a media architecture structure and the immersive technology and the presentation expectation of the design brief. The definition of virtual design environments, media architecture and project presentation possibilities have to be explained more sophisticated.

\section{Confidence}

It has been observed that students are confident in defining media architecture and virtual design environments tools. Students express that media architecture and immersive design tools allow to make more sophisticated design decisions in some circumstances, such as more dynamic installations. The data shows that they are confident to employ in future when they believe it is appropriate.

Learning Format: One student critiqued the confusion about the assignment requirements. They reported it was not clear what was expected regarding the building design, media architecture and final presentation of the project. We communicated the assignment brief open for interpretation to allow students to explore the immersive technology the way they thought it would appreciate. We employed the term narrative technology, which allowed students to interpret in their individual way. It indicates to keep the design brief stricter to achieve a better learning experience. Students demanded to have more explanation for the immersive technologies tools, in addition more time to explore the digital realm themselves. Nevertheless, participants stated that most enquiries during the studio were addressed.

\section{Satisfaction}

Students expressed satisfaction with their design work but highlighted again to wish to have more time to finalise the assignment requirement. They expressed to now be capable of employing a new design tool and have expanded their skill-set. Students were able to communicate their design ideas effectively with the new tools they have been introduced to during the semester. The design proposals they produced were suitable.

\section{Conclusion/ Future Work}

Studies conducted, such as Gross \& Do, 1999; Jenek et al., 2020; Obeid, 2019; Wei et al., 2015 state that there is a lack of research currently on how technologies can be incorporated in the 


\section{Journal of \\ Design Studio}

v:3 n:1 July 2021

education process of architecture students learning about the dynamic properties of media architecture to address real-world issues. Through the study conducted with master students at Queensland University of Technology, educational strategies for dealing with immersive technologies in the context of the homelessness issues were explored in this paper. Through a design brief addressed by the students and their insight into their learning experiences, we could further unpack specific instances supporting exploring technologies in the design studio context. We argue in this paper that there is a scope for immersive technologies to support the design of media architecture to target real-world issues. By designing with immersive technologies, participants discovered the relevance of media architecture as a catalyst for urban life to foster and support marginalized and displaced communities. We propose designing studio education content with allows students to explore dynamic properties such as moving elements, lights and displays.

\section{References}

Australian Government, D. of H. (2021, June 16). 12. Housing and homelessness.

https://www1.health.gov.au/internet/publicatio ns/publishing.nsf/Content/mental-pubs-ppsych10-toc $\sim$ mental-pubs-p-psych10-12

Autodesk. (2021, January 5). Revit. Autodesk. https://www.autodesk.com/products/revit/over view

Braun, V., \& Clarke, V. (2006). Using thematic analysis in psychology. Qualitative Research in Psychology, 3(2), 77-101. https://doi.org/10.1191/1478088706qp063oa

Brynskov, M., Dalsgaard, P., \& Halskov, K. (2015). Media Architecture: Engaging Urban Experiences in Public Space. In J. Lossau \& Q. Stevens (Eds.), The Uses of Art in Public Space (pp. 51-66).

http://site.ebrary.com/id/10994059

Caldwell, G. A. (2016). Media architecture: Facilitating the co-creation of place [10.5204/thesis.eprints.101548].

https://eprints.qut.edu.au/101548/

Caldwell, G. A., \& Foth, M. (2014). DIY media architecture: Open and participatory approaches to community engagement. Proceedings of the 2nd Media Architecture Biennale Conference on World Cities - MAB '14, 1-10. https://doi.org/10.1145/2682884.2682893

Castronovo, F., Oprean, D., Liu, Y., \& Messner, J. (2017). Application of immersive virtual reality systems in an interdisciplinary design studio course. Lean and Computing in Construction Congress (LC3): Volume I Proceedings of the Joint Conference on Computing in Construction (JC3), 337-345.

Chamberlain, C., \& MacKenzie, D. (1992). Understanding contemporary homelessness: Issues of definition and meaning. Australian Journal of Social Issues, 27(4), 274-297.

Dalsgaard, P., \& Halskov, K. (2017). Designing Media Architecture: Methods and Tools. In A. Wiethoff \& H. Hussmann (Eds.), Media architecture: Using information and media as construction material (pp. 125-146). Walter de Gruyter.

Dalsgaard, P., \& Halskov, K. (2010). Designing urban media façades: Cases and challenges. Proceedings of the 28th International Conference on Human Factors in Computing Systems - CHI '10, 2277. https://doi.org/10.1145/1753326.1753670

Desai, P. R., Desai, P. N., Ajmera, K. D., \& Mehta, K. (2014). A review paper on oculus rift-a virtual reality headset. ArXiv Preprint ArXiv:1408.1173.

Epic Games. (2020, November 13). Twinmotioin. Twinmotion. https://www.unrealengine.com/enUS/twinmotion

Fong, \& Chan. (2019, January 23). Media Architecture; Past, Present, Future. Fong \& Chan Architects. 
http://www.fca-

arch.com/insights/2019/1/23/media-

architecture-in-2019

Graphisoft. (2020, November 13). Archicad. Archicad. https://graphisoft.com/

Gross, M., \& Do, E. (1999). Integrating digital media in design studio: Six paradigms. Proceedings of the American College Schools of Architecture Conference, Minneapolis, gub.

Haeusler, M. H., Tomitsch, M., Tscherteu, G., \& Berkel, B. van. (2012). New media facades: A global survey. Avedition.

Hersberger, J. (2005). The homeless and information needs and services. Reference \& User Services Quarterly, 44(3), 199-202.

Huey, L. (2012). Invisible victims: Homelessness and the growing security gap. University of Toronto Press.

Jenek, W., Caldwell, G., Donovan, J., Garcia Hansen, V., Adcock, M., \& Xi, M. (2021). Shaping the future of interactive architecture design: Exploring media architecture design in virtual design environments in a university context. AECURN 2021 Symposium.

Jenek, W., Caldwell, G., Donovan, J., Hansen, V. G., Adcock, M., \& Xi, M. (2020). Exploring Media Architecture Design in Virtual Design Environments. Journal of Design Studio, 2(2), 159-163. https://doi.org/10.46474/jds.825715

Keller, J. M. (2010). Motivational Design for Learning and Performance. Springer US. https://doi.org/10.1007/978-1-4419-1250-3

Knowlton, D. S. (2016). Design studios in instructional design and technology: What are the possibilities? TechTrends, 60(4), 350-358.

Kvan, T. (2001). The pedagogy of virtual design studios. Automation in Construction, 10(3), 345-353.
Le Dantec, C. A., \& Edwards, W. K. (2008). Designs on dignity: Perceptions of technology among the homeless. Proceedings of the SIGCHI Conference on Human Factors in Computing Systems, 627-636.

Lumion. (2021, January 5). Lumion. Lumion. https://lumion.com/

Maher, M. L., Simoff, S. J., \& Cicognani, A. (2012). Understanding virtual design studios. Springer Science \& Business Media.

Obeid, S. (2019). The influence of virtual reality on design process creativity in basic design education [PhD Thesis]. Bilkent University.

Parker, C., Jenek, W., Yoo, S., \& Lee, Y. (2018). Augmenting Cities and Architecture with Immersive Technologies. Proceedings of the 4th Media Architecture Biennale Conference, 174-177.

Wei, X., Weng, D., Liu, Y., \& Wang, Y. (2015). Teaching based on augmented reality for a technical creative design course. Computers \& Education, 81, 221-234. https://doi.org/10.1016/j.compedu.2014.10.017 